\title{
Intramuscular fat in ambulant young adults with bilateral spastic cerebral palsy
}

\author{
Jonathan J Noble ${ }^{1,3^{*}}$, Geoffrey D Charles-Edwards ${ }^{2}$, Stephen F Keevil ${ }^{2}$, Andrew P Lewis ${ }^{1,3}$, Martin Gough ${ }^{3}$ \\ and Adam P Shortland ${ }^{3}$
}

\begin{abstract}
Background: It is known that individuals with bilateral spastic cerebral palsy (BSCP) have small and weak muscles. However, no studies to date have investigated intramuscular fat infiltration in this group. The objective of this study is to determine whether adults with BSCP have greater adiposity in and around their skeletal muscles than their typically developing (TD) peers as this may have significant functional and cardio-metabolic implications for this patient group.

Methods: 10 young adults with BSCP (7 male, mean age 22.5 years, Gross Motor Function Classification System (GMFCS) levels I-III), and 10 TD young adults (6 male, mean age 22.8 years) took part in this study. $11 \mathrm{~cm}$ sections of the left leg of all subjects were imaged using multi-echo gradient echo chemical shift imaging (mDixon). Percentage intermuscular fat (IMAT), intramuscular fat (IntraMF) and a subcutaneous fat to muscle volume ratio (SF/M) were calculated.

Results: IntraMF was higher with BSCP for all muscles ( $p=0.001-0.013)$ and was significantly different between GMFCS levels $(p<0.001)$, with GMFCS level III having the highest IntraMF content. IMAT was also higher with BSCP $p<0.001)$. No significant difference was observed in SF/M between groups.

Conclusion: Young adults with BSCP have increased intermuscular and intramuscular fat compared to their TD peers. The relationship between these findings and potential cardio-metabolic and functional sequelae are yet to be investigated.
\end{abstract}

Keywords: Cerebral palsy, Intramuscular fat, Magnetic resonance imaging, Dixon imaging

\section{Background}

The mechanical potential of muscle depends on gross morphology (cross sectional area, fibre length [1]), muscle fibre type, and muscle composition (fraction of intramuscular fat and connective tissue). Anatomical magnetic resonance imaging (MRI) and ultrasound imaging have demonstrated that the skeletal muscles of the lower limbs of individuals with bilateral spastic cerebral palsy (BSCP) are reduced in size by up to $50 \%$ compared to the muscles of their typically developing (TD) peers [2-4]. However, studies of microstructure and composition

\footnotetext{
* Correspondence: jonathan.noble@gstt.nhs.uk

'Division of Imaging Sciences and Biomedical Engineering, King's College London, The Rayne Institute, 4th Floor, Lambeth Wing, St Thomas' Hospital, London SE1 7EH, United Kingdom

${ }^{3}$ One Small Step Gait Laboratory, Guy's and St Thomas' NHS Foundation Trust, Guy's Hospital, London SE1 9RT, United Kingdom

Full list of author information is available at the end of the article
}

have been limited to a small number of biopsy studies $[5,6]$. In the lower limb, these have demonstrated increases in the connective tissue fraction, reduced muscle fibre diameter, and altered muscle fascicle stiffness $[5,6]$.

Decreased physical activity is associated with increased intermuscular fat [7-10]. Due to the typically sedentary behaviour observed in this group [11,12], one aspect of muscle composition that may be altered in BSCP is the level of intra- and intermuscular fat. Fatty infiltration into muscle results in a reduced proportion of contractile tissue per unit muscle volume. Intramuscular fat also may secrete inflammatory cytokines that can reduce the myofibrillar force even in the absence of muscle atrophy [13]. If present in this group, raised intramuscular fat may have important consequences for physical performance, and implications for exercise regimes employed in their physical management [14]. 
Heightened levels of inter- and intra- muscular fat have been shown to be associated with cardiovascular risk $[15,16]$. Adults with cerebral palsy may have a 2-3 times greater risk of dying from ischemic heart disease than their typically developing peers [17]. However, there are few studies in the literature that have attempted to document body or muscle composition in this group. Since individuals with cerebral palsy have reduced muscle mass, even those with body mass index (BMI) in the normal range may have relatively increased levels of adipose tissue. Previous studies in children with cerebral palsy have suggested raised levels of fat $[18,19]$. In an MRI study of the lower limbs in children with quadriplegic cerebral palsy (Gross Motor Function Classification System (GMFCS) levels III-V), Johnson et al. [18] found increased levels of intermuscular and subcutaneous fat [18]. To date, there have been no studies of intramuscular fat in adults or children with BSCP even though this non-invasively quantified parameter appears to be one of those most associated with cardio-metabolic disease [20].

$\mathrm{T}_{1}$-weighted image segmentation is primarily used to quantify IMAT, with IMAT defined as the MRI-visible fat within the muscles (intramuscular fat) and between the muscles beneath the fascia (intermuscular fat). Although this method is effective for assessing intermuscular and subcutaneous fat volumes, it is not an accurate method for measuring fat distribution within individual muscles. Chemical shift magnetic resonance imaging-based water/ fat separation techniques based on that first proposed by Dixon [21] have been developed which utilise the chemical shift difference between fat and water to enable reconstruction of separate water and fat images. These techniques utilise the predictable difference in phase evolution between water and fat signals due to their chemical shift difference to enable the calculation of separate water and fat images, permitting the calculation of the fat fraction. The fat fraction is the signal intensity attributable to fat, normalised by the total signal from all mobile proton species. These techniques have been widely used in studies quantifying the degree of liver fat in hepatic steatosis (for review see Reeder [22]): although, to date, Dixon imaging has only been used in a small number of clinical intramuscular fat quantification studies $[16,23,24]$.

The aim of this study is to investigate the intermuscular fat (IMAT), subcutaneous fat (SF) and intramuscular fat (IntraMF) content in five major muscles of the leg (medial and lateral gastrocnemius, soleus, tibialis posterior and tibialis anterior) in 10 subjects with BSCP and 10 TD subjects using multi-echo gradient echo chemical shift imaging (mDixon). We hypothesised that the subjects with BSCP would exhibit increased fat content compared to their TD peers.

\section{Methods}

Ethical approval for this study was granted by Hampstead Research Ethics Committee London (09/H0720/120). All subjects gave informed consent before they participated.

\section{Subjects}

Individuals aged 16 - 30 years, with a diagnosis of BSCP, Gross Motor Function Classification System (GMFCS) levels I-III, who met the safety requirements of MRI were included in this study. Patients who had undergone surgery, serial casting or botulinum toxin injections to the lower limbs within the previous year were excluded from the study. This was a convenience sample of individuals attending our hospital department, with consecutive patients that met the inclusion criteria invited to participate in the study.

10 adults with a diagnosis of BSCP (7 male, 3 female, mean age 22.5 years, range 18-27, GMFCS levels I-III from clinics in our university hospital and a convenience sample of 10 TD young adults (6 male, 4 female, mean age 22.8 years, range 18-27) recruited from individuals known to the research team participated in this study. The BSCP subjects had undergone a range of previous interventions (see Table 1) but none had undergone surgery, serial casting or botulinum toxin injections to the lower limbs within the previous year. All TD subjects had no prior significant musculoskeletal trauma or disorders.

\section{Data collection}

MR data were acquired on a 3.0 T Achieva system (Philips Healthcare, Best, The Netherlands) running software version 2.6.3, using an 8-channel receive-only phased array knee coil. One subject had a $30^{\circ}$ knee fixed flexion deformity; instead a 32-channel cardiac coil was used. An $11 \mathrm{~cm}$ section of the left leg was scanned, centred at the largest circumference of the calf with the subject prone. Four point gradient echo mDixon images were

\begin{tabular}{|c|c|}
\hline BSCP subject & Intervention \\
\hline 1 & None \\
\hline 2 & Gastrocnemius lengthening \\
\hline 3 & Gastrocnemius lengthening \\
\hline 4 & None \\
\hline 5 & Gastrocnemius lengthening \\
\hline 6 & Gastrocnemius lengthening \\
\hline 7 & Gastrocnemius lengthening \\
\hline 8 & None \\
\hline 9 & Gastrocnemius and Achilles tendon lengthening \\
\hline 10 & None \\
\hline
\end{tabular}


acquired with $\mathrm{TE} / \mathrm{TR}=2.3 / 7.1 \mathrm{~ms}, 35^{\circ}$ flip angle, $2.0 \times$ $2.0 \mathrm{~mm}$ in-plane resolution, $4.0 \mathrm{~mm}$ slice thickness, echo-time shift $=1.0 \mathrm{~ms}$. Utilising the known chemical shift between water and fat signal constituents, separate water and fat images were calculated within the scanner software. Subject height and body mass were measured in standing before the MRI scan using a stadiometer and calibrated weighing scales. Patients at our centre are routinely classified according to GMFCS level in their medical record by their consulting physician or surgeon.

\section{Data processing}

Regions of interest (ROIs) were manually drawn around the SF, muscle compartment (Figure 1B), and five individual muscles; the soleus, medial gastrocnemius, lateral gastrocnemius, tibialis anterior, and tibialis posterior (Figure 1C), on the mDixon water images using Osirix version 3.7.1 [25]. SF volume was normalised to muscle volume (Equation 1), creating a SF to muscle volume ratio $(\mathrm{SF} / \mathrm{M})$. The ROIs around the entire musculature and individual muscles were eroded with a structuring element size of 2 pixels $(4.0 \mathrm{~mm})$ to remove any potential edge effects with surrounding subcutaneous fat (or intermuscular fat for IntraMF quantification). IMAT and IntraMF were calculated using a ratio of the water and fat signal intensities within the eroded ROIs (Equation 2). The reproducibility of the Dixon technique employed was measured using 5 acquisitions of one TD subject imaged over 3 visits, with the scan repeated twice during 2 of these visits. Reproducibility was defined as the average standard deviation of the measured percentage fat, i.e. the standard deviation averaged across all muscles investigated.

$$
\begin{aligned}
& S F / M=\frac{S F \text { Volume }}{\text { Muscle Volume }} \\
& \% \text { Fat }=100 \times\left(\frac{I_{\text {Fat }}}{I_{\text {Fat }}+I_{\text {Water }}}\right)
\end{aligned}
$$

Where I = Signal intensity.

\section{Data analysis}

Following application of the Kolmogorov-Smirnov test for normality and Levene's test for equality of variance, independent samples t-tests were performed to investigate physical characteristic differences between the two subject groups for all measured parameters. Two-way ANOVA was performed on IntraMF with GMFCS level and muscle identity as fixed factors with a Tukey posthoc test. Non-parametric independent samples median tests compared SF/M and IMAT between groups. The Kruskal-Wallis Test was used to investigate differences in SF/M and IMAT with GMFCS level. Pearson's correlations were used to investigate relationships between measured parameters. All statistical tests were performed using SPSS (Version 20.0; IBM SPSS) with significance set to $\mathrm{p} \leq 0.05$.

\section{Results}

Physical characteristics of subjects in the BSCP and TD groups are summarised in Table 2. There were no group differences in age, body mass, height, or BMI ( $p>0.05$ ). The GMFCS level of the BSCP subjects are also presented in Table 2. The average standard deviation representing reproducibility of intramuscular fat averaged across all muscles was $0.33 \%$.

Figure 2 shows a histogram of group-averaged percentage IntraMF and IMAT. The BSCP group had a significantly higher average percentage IMAT $(\mathrm{p}<0.001)$ and IntraMF compared to the TD group for all muscles investigated $(\mathrm{p}<0.001)$, with the soleus having the largest percentage fat difference $(12.9 \%$ greater in BSCP group). In the BSCP group, IntraMF was significantly correlated between all muscles measured $(r=0.697$ to 0.947, $\mathrm{p}<0.001$ to $\mathrm{p}=0.025$ ) except for the soleus, which did not correlate with any other muscle $(r=0.437$ to $0.587, \mathrm{p}=0.074$ to 0.206 ). Figure 3 shows a histogram of group-averaged SF/M ratio. The mean SF/M ratio was 1.9 times greater in the BSCP group compared to the TD group; however, this difference was not statistically significant $(p=0.179)$. Example images for a case and age-matched control are given in Figure 4.
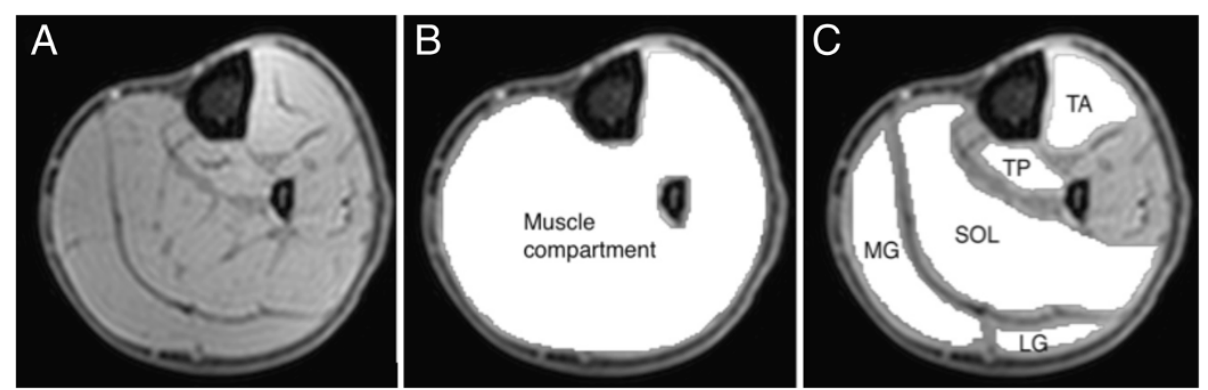

Figure 1 Image segmentation: (A) Example mDixon water image; (B) manually drawn region of interest (white) for the muscle compartment for IMAT segmentation; and (C) the 5 muscles analysed drawn around tibialis anterior (TA), tibialis posterior (TP), soleus (SOL), medial gastrocnemius (MG) and lateral gastrocnemius (LG) for IntraMF segmentation. 
Table 2 Physical characteristics (mean \pm standard deviation) of BSCP and TD groups and number of BSCP subjects in each GMFCS levels (IIIII)

\begin{tabular}{lcc}
\hline & BSCP group & TD group \\
\hline Number of subjects & 10 & 10 \\
Age (years) & $22.5 \pm 2.9$ & $22.8 \pm 3.0$ \\
Sex $(\mathrm{m}, \mathrm{f})$ & 7,3 & 6,4 \\
Body mass $(\mathrm{kg})$ & $64.0 \pm 11.5$ & $71.2 \pm 11.8$ \\
Height $(\mathrm{m})$ & $1.69 \pm 0.08$ & $1.76 \pm 0.12$ \\
BMI $\left(\mathrm{kg} / \mathrm{m}^{2}\right)$ & $22.4 \pm 3.6$ & $22.9 \pm 1.7$ \\
GMFCS level I & 2 & $\mathrm{~N} / \mathrm{A}$ \\
GMFCS level II & 5 & $\mathrm{~N} / \mathrm{A}$ \\
GMFCS level III & 3 & $\mathrm{~N} / \mathrm{A}$ \\
\hline
\end{tabular}

One-way ANOVA and post hoc analysis revealed significant differences in IntraMF levels by GMFCS level ( $\mathrm{p}<0.001$ ), with GMFCS level III significantly higher compared to GMFCS levels I and II ( $p<0.001$ and $p=0.001$ respectively). No significant difference was observed in IMAT or SF/M with GMFCS level $(p=0.131)$. In the TD group, SF/M was correlated with IMAT $(r=0.81$, $\mathrm{p}=0.005)$ but not with IntraMF $(\mathrm{r}=0.182, \mathrm{p}=0.206)$, and no correlation was observed between IMAT and IntraMF $(r=0.251, p=0.079)$. In the BSCP group, no correlations were observed between SF/M and IMAT $(\mathrm{r}=0.392, \mathrm{p}=0.262)$ or IntraMF $(\mathrm{r}=0.134, \mathrm{p}=0.353)$; IMAT and IntraMF were significantly correlated $(r=0.529$, $\mathrm{p}<0.001)$.

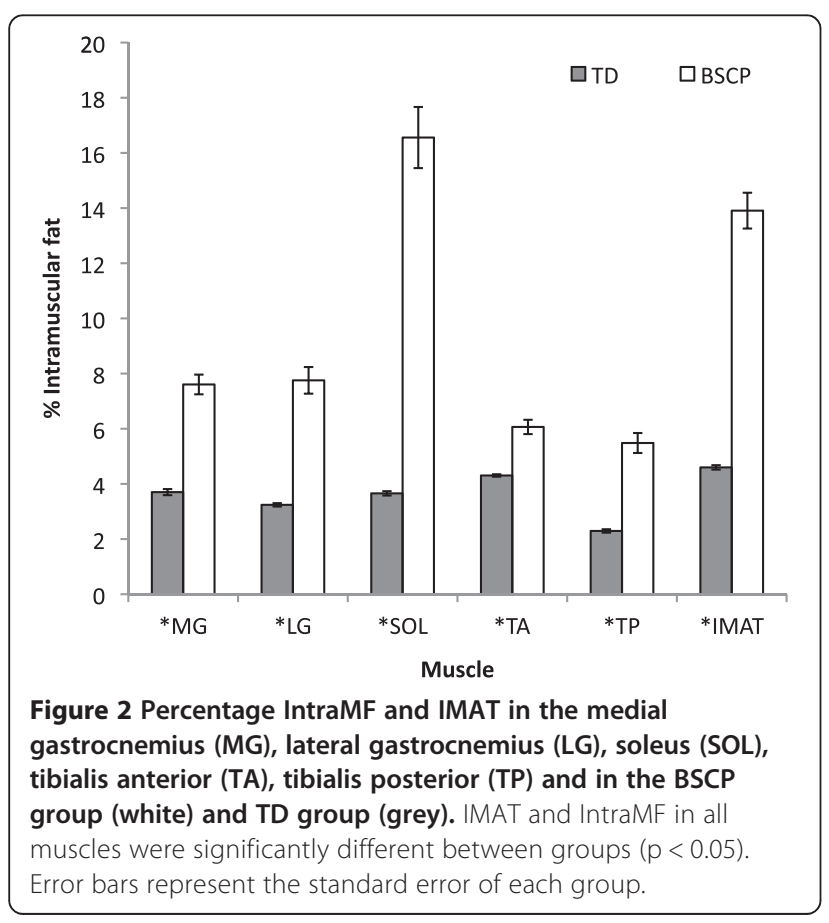

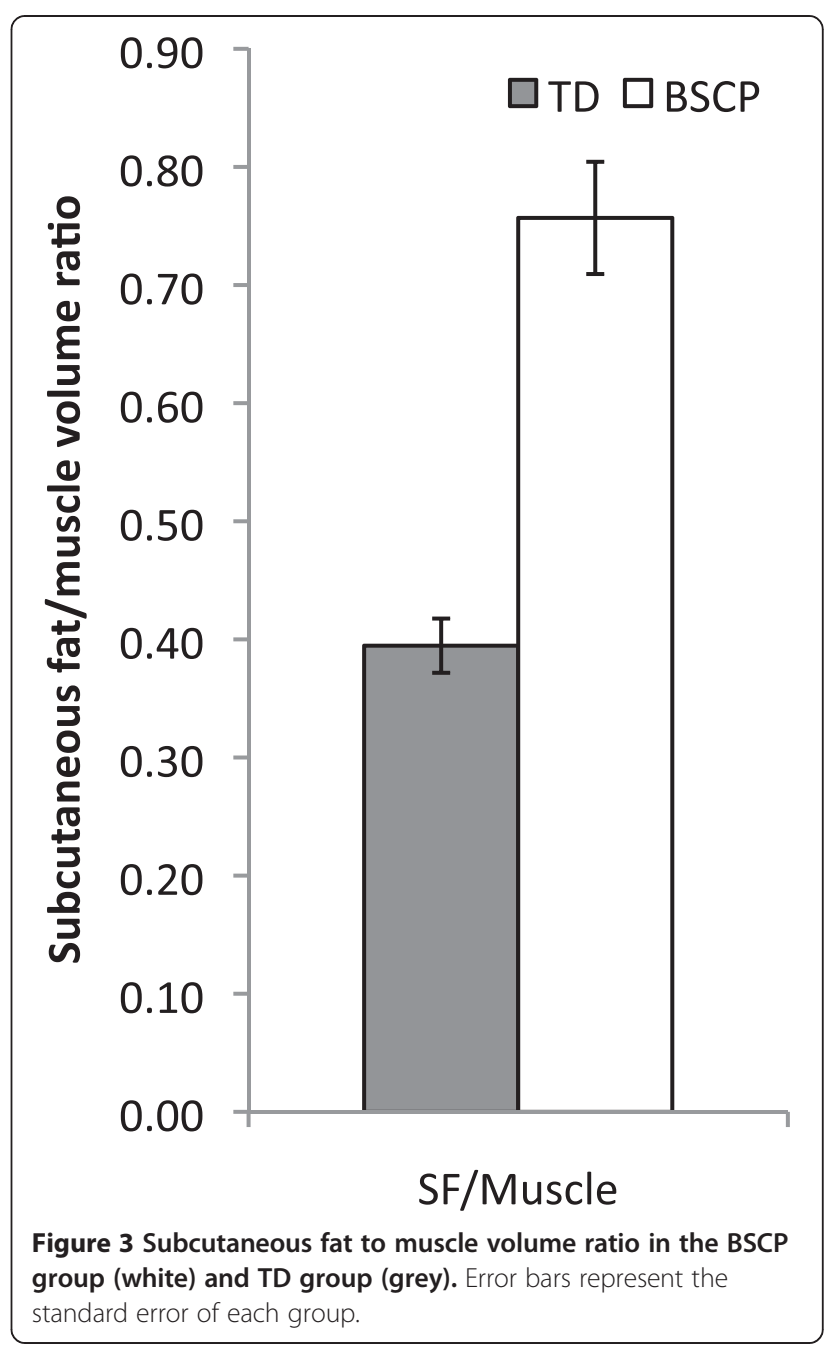

\section{Discussion}

We conducted MRI measurements of IMAT, SF/M ratio, and IntraMF on 10 young adults with BSCP and 10 of their TD peers. This is the first study to show that ambulant adults with BSCP have raised levels of IntraMF, ranging from 2.3 to $34.4 \%$. Percentage IntraMF was also found to be significantly different between GMFCS levels, with those at GMFCS III having greater fatty infiltration. These differences in IntraMF by GMFCS level suggest IntraMF maybe related to the degree of mobility impairment. This may be due to decreased physical activity with increasing mobility impairments.

The 1.9 fold greater SF/M ratio in the BSCP group is comparable to the results of Johnson et al. [18], who reported 2 fold greater SF/M ratio in the mid thigh of children with quadriplegic cerebral palsy GMFCS levels III-V [18]. This is surprising due to the higher functional ability of the subjects in this study (GMFCS levels I-III). IMAT values cannot be compared between these studies due to the separation by Johnson et al. of IMAT into 

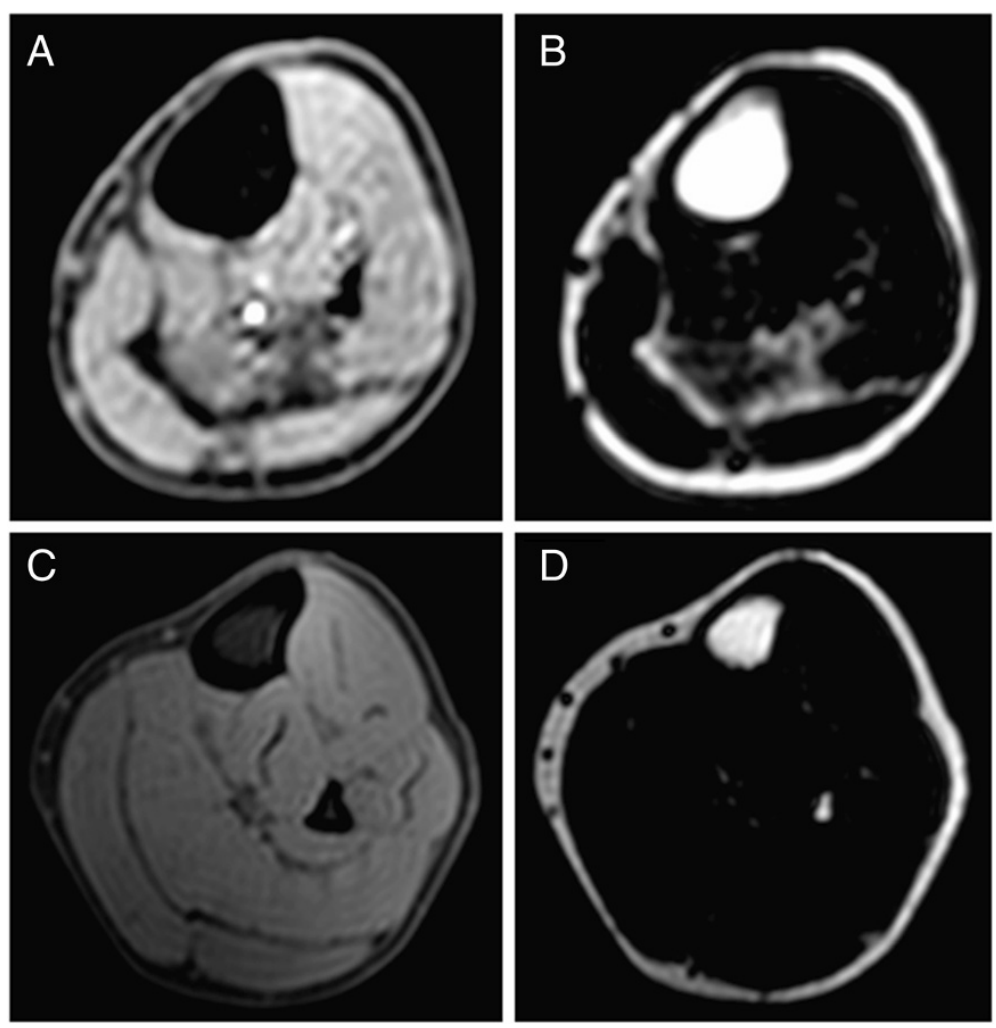

Figure 4 Example water (A and C) and fat (B and D) for one subject with BSCP (A and B), and an age matched TD subject (C and D).

intermuscular and sub-fascial fat and the different imaging and analysis techniques employed.

\section{Clinical implications}

Children and young adults with cerebral palsy have been shown to have reduced muscle volumes in their lower limbs [2-4,26-30] and increased IMAT [18]. This study demonstrates that these muscles also have greater levels of intramuscular fat that is independent of subcutaneous fat levels. This combination of morphological and compositional changes may have implications both for the mechanical performance of these skeletal muscles and also for the predisposition of the adult with BSCP to cardio-metabolic disease [20].

Muscle weakness is a prevalent feature of individuals with cerebral palsy $[26,31,32]$. Muscle weakness, in this group, is in part caused by an inability to fully activate available muscular resources [33], increased co-activation [34] and by reduced muscle volume [2-4,26-30]. For a given muscle volume, a higher intramuscular fat content will correspond to reduced contractile tissue content, resulting in a weaker muscle than predicted from muscle mass alone. Furthermore, inflammatory cytokines produced by intramuscular fat may interfere with the action of myofibrillar proteins reducing specific force production [13]. These secondary pathologies may contribute to a deficit in the "functional reserve" of adults with BSCP, and may expose these individuals to a heightened risk of immobility with increasing age [30].

Greater intramuscular fat content in BSCP may expose these individuals to a greater risk of developing cardiometabolic disease [20]. There is a strong relationship between intramuscular fat content, insulin resistance and type-II diabetes $[15,35,36]$. Within skeletal muscle, fat is stored in two separate compartments: Intramyocellular lipid (IMCL) and extramyocellular lipid (EMCL). EMCL is found within adipose cells adjacent to the muscle fibres, and IMCL is located along with enzymes involved in fatty acid esterification, hydrolysis, and transport into the mitochondria [37]. Enhanced storage of IMCL occurs due to the combined effects of high concentration of serum insulin and free fatty acids [38]. In particular, greater IMCL in the soleus correlates with glucose-insulin-lipid metabolism and insulin sensitivity [39-42], with soleus IMCL content being the only differentiating feature in a study of lean insulin-resistant subjects and their TD peers matched for BMI, body fat distribution, percentage body fat and physical fitness [42]. However, IntraMF quantification using Dixon imaging techniques measure IMCL and EMCL as a composite. IMCL has been shown to be unrelated to measures of adiposity $[39,43]$. In this study IntraMF did not correlate with SF/M. This suggests that the raised IntraMF 
measured in BSCP may be due to greater IMCL content. However, although the mDixon scans showed raised IntraMF with BSCP, whether this is due to raised IMCL, EMCL, or both is not yet known. Therefore, further investigations are required using magnetic resonance spectroscopy to determine the contributions of IMCL and EMCL to the raised IntraMF observed in this study.

Greater intramuscular fat may also be a marker of impaired mitochondrial content and/or function [44]. The increased intramuscular fat content observed in this study, particularly in the soleus, indicates that patients with cerebral palsy may have a greater risk of developing obesity related diseases, particularly type-II diabetes. Since IntraMF was observed to be greater with increasing GMFCS level, this risk of obesity-related disease may increase with decreasing functional ability. However, intramuscular fat is only one factor associated with the risk of developing obesity related diseases. Future studies of activity levels, fat levels, and glucose tolerance, are required to investigate the risk developing cardio-metabolic diseases in this patient group.

Greater intramuscular fat can be caused by a chronic mismatch between energy intake and expenditure [26,45]. Such a mismatch would also result in greater subcutaneous fat levels. In this study, however, despite SF/M being greater in the BSCP group, this was not statistically significant. This suggests that other factors as well as any potential energy mismatch are adversely affecting the intramuscular fat content in BSCP.

IntraMF has been correlated with deficits in central muscle activation [46], increased risk of future mobility loss $[47,48]$, and insulin resistance [49] in the elderly population. Preliminary studies have also shown that particular exercise regimes in older adults may prevent and decrease intramuscular fat [10]. Since skeletal muscle in cerebral palsy has similarities with muscles in the elderly, including reduced muscle volume [50], increased stiffness [51] and reduced voluntary muscle activation [33], these exercise studies could have important implications for the physical management of this group as suggested by Peterson et al. [14].

\section{Limitations}

The number of subjects recruited may limit the scope and power of this study. However, the differences in intramuscular fat between the TD and BSCP groups were large and statistically significant. The group differences were also much larger than the reproducibility of the mDixon technique used in this study, defined as the average standard deviation of measured percentage fat across all muscles $(0.33 \%)$.

Despite having good accuracy and reproducibility, fatfractions measured using multi-echo techniques are not standardised and platform-independent. The precision of the quantified fat fraction depends on five confounding factors; T1 bias, T2* decay, spectral complexity of fat, noise bias, and eddy currents [22]. The T1 bias and the assumption that fat has a single frequency peak, results in an inadvertent misidentification of some signal from fat as arising from water, and hence to quantification errors [52]. The $\mathrm{T} 1$ bias is due to the $\mathrm{T} 1$ weighting of the mDixon sequence, in order to reduce scan time. When there is partial-volume mixing of fat and muscle tissue within pixels, signal from fat, which has a shorter T1 than water, is overestimated. Therefore, despite being suitable for comparisons within single site studies, comparison of absolute values of intramuscular fat quantified in this study across sites where different techniques and sequence designs have been employed will be more difficult.

Six of the ten BSCP subjects had undertaken gastrocnemius recessions to the left leg; with one of these six subjects also having had Achilles tendon lengthening. Since muscle injury can lead to fatty degradation of muscle tissue [53-56], it is possible that the histories of surgical intervention received by the individuals with BSCP in this study may have influenced the development of particular muscles. A histogram comparing the percentage intramuscular fat between the TD group, BSCP subjects with no intervention, and BSCP subjects who have previously received gastrocnemius lengthening is given in Figure 5. Percentage intramuscular fat was significantly dependent on intervention and muscle $(\mathrm{p}=0.048$ and $\mathrm{p}=0.009$ respectively). Despite not being operated on directly, the soleus had significantly higher intramuscular fat content compared to MG and LG ( $\mathrm{p}=0.006$ and $\mathrm{p}=0.007$ respectively). This data suggests that gastrocnemius lengthening may result in damage to the soleus causing fatty accumulation. Longitudinal studies are required to determine whether surgery results in greater accumulation of intramuscular fat, or whether those with heightened levels of intramuscular fat are more likely to have surgery.

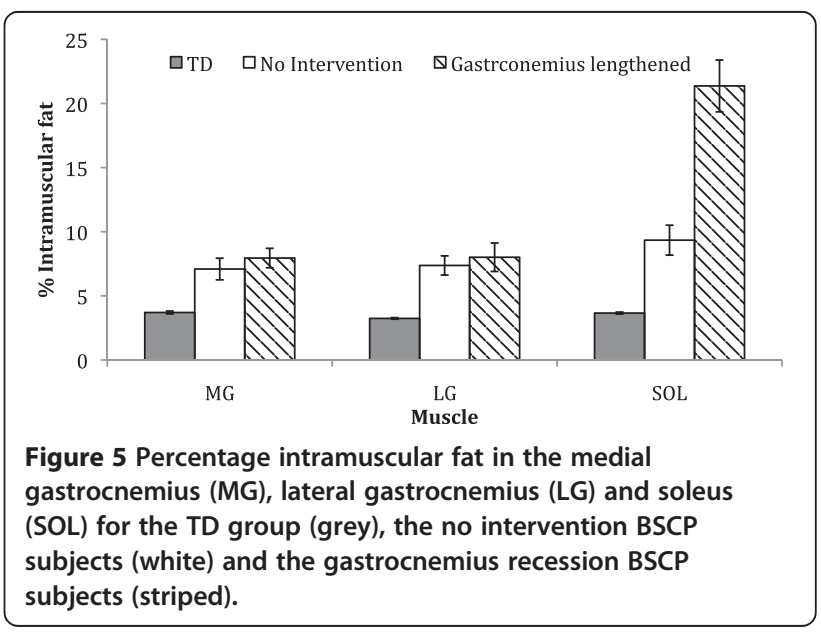


The subjects groups were not age, BMI, and sex matched: however, the physical characteristic differences between the two groups were minimal with no significant difference in age, body mass, height, or BMI observed between the groups. It is possible that the large differences in fat levels in BSCP are due to large differences in life style, including activity levels and diet. Alternatively, the greater fat levels observed in this study may be due to an inherent predisposition with BSCP. To assess the contribution of the factors, further research is required to identify the cause of the increased intramuscular fat in BSCP.

\section{Conclusion}

Greater intramuscular fat and IMAT is found in BSCP compared to their TD peers; with the amount of intramuscular fat related to GMFCS level. Despite normal BMIs, the patients in this group may have an increased risk of developing obesity-related diseases, with risk increasing with decreasing functional ability. Furthermore, the increasing intramuscular fat content may help to explain deficits in muscle performance in this group.

\section{Abbreviations}

BMI: Body Mass Index; BSCP: Bilateral Spastic Cerebral Palsy;

EMCL: Extramyocellular lipid; GMFCS: Gross Motor Function Classification System; IMCL: Intramyocellular lipid; LG: Lateral Gastrocnemius; MG: Medial Gastrocnemius; MRI: Magnetic Resonance Imaging; ROls: Regions of interest; SOL: Soleus; SF: Subcutaneous fat; SF/M: Subcutaneous to muscle volume ratio; TA: Tibialis Anterior; TD: Typically developing; TP: Tibialis Posterior.

\section{Competing interests}

The authors declare that they have no competing interests.

\section{Authors' contributions}

JJN was responsible for study design, MRI sequence development, data collection, data analysis and interpretation, and drafted the manuscript. GDE Assisted in study design, sequence development, data collection, and helped to draft the manuscript. SFK assisted in study design and helped to draft the manuscript. APL assisted in data analysis and helped to draft the manuscript. MG assisted in study design, subject recruitment, data interpretation, and helped to draft the manuscript. APS was responsible for conception and assisted in study design, data analysis and interpretation and helped to draft the manuscript. All authors read and approved the final manuscript.

\section{Acknowledgements}

Jonathan Noble was funded on a PhD studentship from the Guy's and St. Thomas's Charity, London, UK. This research was supported by the National Institute for Health Research (NIHR) Biomedical Research Centre at Guy's and St Thomas' NHS Foundation Trust and King's College London. The views expressed are those of the author(s) and not necessarily those of the NHS, the NIHR or the Department of Health.

\section{Author details}

'Division of Imaging Sciences and Biomedical Engineering, King's College London, The Rayne Institute, 4th Floor, Lambeth Wing, St Thomas' Hospital, London SE1 7EH, United Kingdom. '2Department of Medical Physics, Guy's and St Thomas' NHS Foundation Trust, The Rayne Institute, 4th Floor, Lambeth Wing, St Thomas' Hospital, London SE1 7EH, United Kingdom. ${ }^{3}$ One Small Step Gait Laboratory, Guy's and St Thomas' NHS Foundation Trust, Guy's Hospital, London SE1 9RT, United Kingdom.

Received: 25 October 2013 Accepted: 1 July 2014

Published: 12 July 2014

\section{References}

1. Lieber RL, Friden J: Functional and clinical significance of skeletal muscle architecture. Muscle Nerve 2000, 23(11):1647-1666.

2. Fry NR, Gough M, McNee AE, Shortland AP: Changes in the volume and length of the medial gastrocnemius after surgical recession in children with spastic diplegic cerebral palsy. J Pediatr Orthop 2007, 27(7):769-774.

3. Oberhofer K, Stott NS, Mithraratne K, Anderson IA: Subject-specific modelling of lower limb muscles in children with cerebral palsy. Clin Biomech (Bristol, Avon) 2010, 25(1)):88-94.

4. Noble JJ, Fry NR, Lewis AP, Keevil SF, Gough M, Shortland AP: Lower limb muscle volumes in bilateral spastic cerebral palsy. Brain Dev 2013, 36(4):294-300.

5. Booth CM, Cortina-Borja MJ, Theologis TN: Collagen accumulation in muscles of children with cerebral palsy and correlation with severity of spasticity. Dev Med Child Neurol 2001, 43(5):314-320.

6. Lieber RL, Runesson E, Einarsson F, Friden J: Inferior mechanical properties of spastic muscle bundles due to hypertrophic but compromised extracellular matrix material. Muscle Nerve 2003, 28(4):464-471.

7. Manini TM, Clark BC, Nalls MA, Goodpaster BH, Ploutz-Snyder LL, Harris TB: Reduced physical activity increases intermuscular adipose tissue in healthy young adults. Am J Clin Nutr 2007, 85(2):377-384.

8. Tuttle LJ, Sinacore DR, Cade WT, Mueller MJ: Lower physical activity is associated with higher intermuscular adipose tissue in people with type 2 diabetes and peripheral neuropathy. Phys Ther 2011, 91(6):923-930.

9. Leskinen $\mathrm{T}$, Sipila $\mathrm{S}$, Alen $\mathrm{M}$, Cheng $\mathrm{S}$, Pietilainen $\mathrm{KH}$, Usenius JP, Suominen $H$, Kovanen V, Kainulainen H, Kaprio J, Kujala UM: Leisure-time physical activity and high-risk fat: a longitudinal population-based twin study. Int J Obes (Lond) 2009, 33(11):1211-1218.

10. Goodpaster BH, Chomentowski P, Ward BK, Rossi A, Glynn NW, Delmonico MJ, Kritchevsky SB, Pahor M, Newman AB: Effects of physical activity on strength and skeletal muscle fat infiltration in older adults: a randomized controlled trial. J App/ Physiol 2008, 105(5):1498-1503.

11. Gaskin CJ, Morris T: Physical activity, health-related quality of life, and psychosocial functioning of adults with cerebral palsy. J Phys Act Health 2008, 5(1):146-157

12. van Eck M, Dallmeijer AJ, Beckerman $H$, van den Hoven PA, Voorman JM, Becher JG: Physical activity level and related factors in adolescents with cerebral palsy. Pediatr Exerc Sci 2008, 20(1):95-106.

13. Hardin BJ, Campbell KS, Smith JD, Arbogast S, Smith J, Moylan JS, Reid MB: TNF-alpha acts via TNFR1 and muscle-derived oxidants to depress myofibrillar force in murine skeletal muscle. J Appl Physiol 2008, 104(3):694-699.

14. Peterson MD, Gordon PM, Hurvitz EA: Chronic disease risk among adults with cerebral palsy: the role of premature sarcopoenia, obesity and sedentary behaviour. Obes Rev 2012, 14(2):171-182.

15. Elder CP, Apple DF, Bickel CS, Meyer RA, Dudley GA: Intramuscular fat and glucose tolerance after spinal cord injury-a cross-sectional study. Spinal Cord 2004, 42(12):711-716.

16. Kovanlikaya A, Mittelman SD, Ward A, Geffner ME, Dorey F, Gilsanz V: Obesity and fat quantification in lean tissues using three-point Dixon MR imaging. Pediatr Radiol 2005, 35(6):601-607.

17. Strauss D, Cable W, Shavelle R: Causes of excess mortality in cerebral palsy. Dev Med Child Neurol 1999, 41(9):580-585.

18. Johnson DL, Miller F, Subramanian P, Modlesky CM: Adipose tissue infiltration of skeletal muscle in children with cerebral palsy. J Pediatr 2009, 154(5):715-720.

19. Bandini LG, Schoeller DA, Fukagawa NK, Wykes $\sqcup$, Dietz WH: Body composition and energy expenditure in adolescents with cerebral palsy or myelodysplasia. Pediatr Res 1991, 29(1):70-77

20. Bauman WA: The potential metabolic consequences of cerebral palsy: inferences from the general population and persons with spinal cord injury. Dev Med Child Neurol 2009, 51(Suppl 4):64-78.

21. Dixon WT: Simple proton spectroscopic imaging. Radiology 1984 153(1):189-194.

22. Reeder SB, Sirlin CB: Quantification of liver fat with magnetic resonance imaging. Magn Reson Imaging Clin N Am 2010, 18(3):337-357. ix.

23. Karampinos DC, Baum T, Nardo L, Alizai H, Yu H, Carballido-Gamio J, Yap SP, Shimakawa A, Link TM, Majumdar S: Characterization of the regional distribution of skeletal muscle adipose tissue in type 2 diabetes using chemical shift-based water/fat separation. J Magn Reson Imaging 2012, 35(4):899-907. 
24. Wren TA, Bluml S, Tseng-Ong L, Gilsanz V: Three-point technique of fat quantification of muscle tissue as a marker of disease progression in Duchenne muscular dystrophy: preliminary study. AJR Am J Roentgenol 2008, 190(1):W8-W12.

25. Rosset A, Spadola L, Ratib O: OsiriX: an open-source software for navigating in multidimensional DICOM images. J Digit Imaging 2004, 17(3):205-216.

26. Elder GC, Kirk J, Stewart G, Cook K, Weir D, Marshall A, Leahey L: Contributing factors to muscle weakness in children with cerebral palsy. Dev Med Child Neurol 2003, 45(8):542-550.

27. Barber L, Hastings-Ison T, Baker R, Barrett R, Lichtwark G: Medial gastrocnemius muscle volume and fascicle length in children aged 2 to 5 years with cerebral palsy. Dev Med Child Neurol 2011, 53(6):543-548.

28. Barrett RS, Lichtwark GA: Gross muscle morphology and structure in spastic cerebral palsy: a systematic review. Dev Med Child Neurol 2010, 52(9):794-804

29. Malaiya R, McNee AE, Fry NR, Eve LC, Gough M, Shortland AP: The morphology of the medial gastrocnemius in typically developing children and children with spastic hemiplegic cerebral palsy. J Electromyogr Kinesiol 2007, 17(6):657-663.

30. Shortland A: Muscle deficits in cerebral palsy and early loss of mobility: can we learn something from our elders? Dev Med Child Neurol 2009, 51(Suppl 4):59-63.

31. Poon DM, Hui-Chan CW: Hyperactive stretch reflexes, co-contraction, and muscle weakness in children with cerebral palsy. Dev Med Child Neurol 2009, 51(2):128-135.

32. Wiley ME, Damiano DL: Lower-extremity strength profiles in spastic cerebral palsy. Dev Med Child Neurol 1998, 40(2):100-107.

33. Stackhouse SK, Stevens JE, Lee SC, Pearce KM, Snyder-Mackler L, Binder-Macleod SA: Maximum voluntary activation in nonfatigued and fatigued muscle of young and elderly individuals. Phys Ther 2001, 81(5):1102-1109.

34. Stackhouse SK, Binder-Macleod SA, Lee SC: Voluntary muscle activation, contractile properties, and fatigability in children with and without cerebral palsy. Muscle Nerve 2005, 31(5):594-601.

35. Kewalramani G, Bilan PJ, Klip A: Muscle insulin resistance: assault by lipids, cytokines and local macrophages. Curr Opin Clin Nutr Metab Care 2010, 13(4):382-390

36. Lara-Castro C, Garvey WT: Intracellular lipid accumulation in liver and muscle and the insulin resistance syndrome. Endocrinol Metab Clin North Am 2008, 37(4):841-856.

37. Schick F, Eismann B, Jung WI, Bongers H, Bunse M, Lutz O: Comparison of localized proton NMR signals of skeletal muscle and fat tissue in vivo: two lipid compartments in muscle tissue. Magn Reson Med 1993 29(2):158-167.

38. Brechtel K, Dahl DB, Machann J, Bachmann OP, Wenzel I, Maier T, Claussen $C D$, Haring HU, Jacob S, Schick F: Fast elevation of the intramyocellular lipid content in the presence of circulating free fatty acids and hyperinsulinemia: a dynamic 1H-MRS study. Magn Reson Med 2001, 45(2):179-183.

39. Krssak M, Falk Petersen K, Dresner A, DiPietro L, Vogel SM, Rothman DL, Roden M, Shulman Gl: Intramyocellular lipid concentrations are correlated with insulin sensitivity in humans: a 1H NMR spectroscopy study. Diabetologia 1999, 42(1):113-116.

40. Petersen KF, Hendler R, Price T, Perseghin G, Rothman DL, Held N, Amatruda JM, Shulman Gl: 13C/31P NMR studies on the mechanism of insulin resistance in obesity. Diabetes 1998, 47(3):381-386.

41. Misra A, Sinha S, Kumar M, Jagannathan NR, Pandey RM: Proton magnetic resonance spectroscopy study of soleus muscle in non-obese healthy and Type 2 diabetic Asian Northern Indian males: high intramyocellular lipid content correlates with excess body fat and abdominal obesity. Diabet Med 2003, 20(5):361-367

42. Jacob S, Machann J, Rett K, Brechtel K, Volk A, Renn W, Maerker E, Matthaei S, Schick F, Claussen CD, Haring HU: Association of increased intramyocellular lipid content with insulin resistance in lean nondiabetic offspring of type 2 diabetic subjects. Diabetes 1999, 48(5):1113-1119.

43. Pan DA, Lillioja S, Kriketos AD, Milner MR, Baur LA, Bogardus C, Jenkins AB, Storlien LH: Skeletal muscle triglyceride levels are inversely related to insulin action. Diabetes 1997, 46(6):983-988.

44. Stump CS, Henriksen EJ, Wei Y, Sowers JR: The metabolic syndrome: role of skeletal muscle metabolism. Ann Med 2006, 38(6):389-402.
45. Ryan AS, Dobrovolny CL, Smith GV, Silver KH, Macko RF: Hemiparetic muscle atrophy and increased intramuscular fat in stroke patients. Arch Phys Med Rehabil 2002, 83(12):1703-1707.

46. Yoshida Y, Marcus RL, Lastayo PC: Intramuscular adipose tissue and central activation in older adults. Muscle Nerve 2012, 46(5):813-816.

47. Visser M, Kritchevsky SB, Goodpaster BH, Newman AB, Nevitt M, Stamm E, Harris TB: Leg muscle mass and composition in relation to lower extremity performance in men and women aged 70 to 79: the health, aging and body composition study. J Am Geriatr Soc 2002, 50(5):897-904.

48. Marcus RL, Addison O, Dibble LE, Foreman KB, Morrell G, Lastayo P: Intramuscular adipose tissue, sarcopenia, and mobility function in older individuals. J Aging Res 2012, 2012:629637.

49. Petersen KF, Befroy D, Dufour S, Dziura J, Ariyan C, Rothman DL, DiPietro L, Cline GW, Shulman Gl: Mitochondrial dysfunction in the elderly: possible role in insulin resistance. Science 2003, 300(5622):1140-1142.

50. Faulkner JA, Larkin LM, Claflin DR, Brooks SV: Age-related changes in the structure and function of skeletal muscles. Clin Exp Pharmacol Physiol 2007, 34(11):1091-1096.

51. Alnaqeeb MA, Al Zaid NS, Goldspink G: Connective tissue changes and physical properties of developing and ageing skeletal muscle. J Anat 1984, 139(Pt 4):677-689.

52. Yokoo T, Bydder M, Hamilton G, Middleton MS, Gamst AC, Wolfson T, Hassanein T, Patton HM, Lavine JE, Schwimmer JB, Sirlin CB: Nonalcoholic fatty liver disease: diagnostic and fat-grading accuracy of low-flip-angle multiecho gradient-recalled-echo MR imaging at 1.5 T. Radiology 2009, 251(1):67-76.

53. Gerber C, Fuchs B, Hodler J: The results of repair of massive tears of the rotator cuff. J Bone Joint Surg Am 2000, 82(4):505-515.

54. Liu W, Liu Y, Lai X, Kuang S: Intramuscular adipose is derived from a non-Pax3 lineage and required for efficient regeneration of skeletal muscles. Dev Biol 2012, 361(1):27-38.

55. Contreras-Shannon V, Ochoa O, Reyes-Reyna SM, Sun D, Michalek JE, Kuziel WA, McManus LM, Shireman PK: Fat accumulation with altered inflammation and regeneration in skeletal muscle of CCR2-/- mice following ischemic injury. Am J Physiol Cell Physiol 2007, 292(2):C953-C967.

56. Gumucio JP, Davis ME, Bradley JR, Stafford PL, Schiffman CJ, Lynch EB, Claflin DR, Bedi A, Mendias CL: Rotator cuff tear reduces muscle fiber specific force production and induces macrophage accumulation and autophagy. J Orthop Res 2012, 30(12):1963-1970.

doi:10.1186/1471-2474-15-236

Cite this article as: Noble et al:: Intramuscular fat in ambulant young adults with bilateral spastic cerebral palsy. BMC Musculoskeletal Disorders 2014 15:236.

\section{Submit your next manuscript to BioMed Central and take full advantage of:}

- Convenient online submission

- Thorough peer review

- No space constraints or color figure charges

- Immediate publication on acceptance

- Inclusion in PubMed, CAS, Scopus and Google Scholar

- Research which is freely available for redistribution 